\title{
Role of FAT1 in health and disease (Review)
}

\author{
ZIZHEN PENG, YANYU GONG and XIAOQIU LIANG
}

\begin{abstract}
Hunan Province Key Laboratory of Tumor Cellular and Molecular Pathology, Cancer Research Institute, Hengyang School of Medicine, University of South China, Hengyang, Hunan 421001, P.R. China
\end{abstract}

Received September 23, 2020; Accepted February 25, 2021

DOI: $10.3892 / \mathrm{ol} .2021 .12659$

\begin{abstract}
FAT atypical cadherin 1 (FAT1), which encodes a protocadherin, is one of the most frequently mutated genes in human cancer. Over the past 20 years, the role of FAT1 in tissue growth and in the development of diseases has been extensively studied. There is definitive evidence that FAT1 serves a substantial role in the maintenance of organs and development, and its expression appears to be tissue-specific. FAT1 activates a variety of signaling pathways through protein-protein interactions, including the $\mathrm{Wnt} / \beta$-catenin, Hippo and MAPK/ERK signaling pathways, which affect cell proliferation, migration and invasion. Abnormal FAT1 expression may lead to the development of tumors and may affect prognosis. Therefore, FAT1 may have potential in tumor therapy. The structural and functional changes mediated by FAT1, its tissue distribution and changes in FAT1 expression in human diseases are described in the present review, which provides further insight for understanding the role of FAT1 in development and disease.
\end{abstract}

\section{Contents}

1. Introduction

2. Signaling pathways and mechanisms

3. FAT1 in development

4. FAT1 in hereditary diseases

5. FAT1 in cancer

6. Therapeutic targeting of FAT1

7. Conclusions and perspectives

Correspondence to: Professor Xiaoqiu Liang, Hunan Province Key Laboratory of Tumor Cellular and Molecular Pathology, Cancer Research Institute, Hengyang School of Medicine, University of South China, 28 Changsheng West Street, Hengyang, Hunan 421001, P.R. China

E-mail: kurkova314@126.com

Key words: FAT atypical cadherin 1, FAT cadherins, Wnt signaling pathway, Hippo signaling pathway, cancer

\section{Introduction}

Intercellular adhesion is the structural basis for the growth and development of multicellular organisms. The abnormal expression of proteins involved in the process of intercellular adhesion can cause various complications, such as kidney, cardiovascular and autoimmune diseases, as well as cancer (1-3). Cadherins are essential for cell adhesion. In vertebrates, it is generally accepted that there are six main subfamilies of cadherins: Classical cadherins, desmosomal cadherins, protocadherins, Flamingo/Celsr, Dachsous and FAT atypical cadherins (FAT) (4).

In the 1920s, FAT was discovered in Drosophila due to a lethal mutation (5). Drosophila has two FAT cadherin members, Ft and Ft2, which are considered tumor suppressors (6). Most functional mutations of the Ft gene result in an 'epithelial overgrowth phenotype' in Drosophila larvae, which can affect the wings, legs, eye antennae, glands and genital imaging disc $(6,7)$. The overgrowth phenotype observed following Ft inactivation is hypothesized to be partly associated with the fact that Ft can affect the localization and expression levels of the Hippo signaling pathway transcription factors, Yorkie (Yki), Warts (Wts) and Expanded (8-10). In addition, in the eyes of FAT mutant Drosophila, the omentum exhibits reversed dorsal-ventral polarity (11). This is hypothesized to be caused by the effect of Ft on planar cell polarity (PCP) (11). The other FAT cadherin member in Drosophila, Ft2, is necessary for morphogenesis and maintenance of tubular structures of ectodermal origin $(7,12)$. Deletion of $\mathrm{Ft} 2$ results in abnormal development of renal tubular structures, such as loss of the trachea, gastric glands and salivary glands (12). The established functional roles of Ft and Ft2 in Drosophila primarily include regulation of morphogenesis, growth control and PCP $(8,11,12)$, providing a platform for the study of FAT cadherins in vertebrates.

From Drosophila to vertebrates, the FAT cadherin family has expanded from two members to four, but their structure and function remain conserved across species (13). The FAT cadherin family in vertebrates consists of FAT1-4 (5), all of which have unique arrangements and number of laminin $G$ motifs and EGF-like motifs, which bestows upon them unique functions. FAT1 and FAT4 contain 34 extracellular cadherin repeats, whereas FAT2 contains 32 repeats and FAT3 contains 33 repeats (Fig. 1) (14). As FAT mRNA transcripts and coding proteins are large, understanding the function of FAT proteins is challenging. At present, the majority of research on FAT 
proteins have focused on FAT1, as FAT1 was the first member to be identified in humans, and the effects of FAT1 mutations in tumors, such as acute lymphoblastic leukemia (ALL) (15) and hepatocellular carcinoma (HCC) (16), are more prominent (7).

The human FAT1 gene was cloned from a human T-cell ALL (T-ALL) cell line in 1995 (15). The gene is located on chromosome 4q34-35 and consists of 27 exons in humans (15). It is a type I transmembrane protein, consisting of an extracellular region, transmembrane region and cytoplasmic tail (17).

It has been reported that FAT1 is involved in numerous processes, such as cell adhesion, proliferation and migration via protein-protein interactions of its cytoplasmic tail (7). Existing evidence has shown that FAT1 can bind to the actin-regulatory protein Enabled (Ena)/vasodilator-stimulated phosphoprotein (Vasp) and $\beta$-catenin to regulate cell proliferation and migration, and that it serves a role in the $\mathrm{Wnt} / \beta$-catenin, Hippo and MAPK/ERK signaling pathways, as well affecting epithelial-mesenchymal transition (EMT) (18-22). At present, knowledge regarding the exact downstream signaling pathways mediated by FAT1 remains incomplete, but an increasing body of knowledge is indicating that changes in FAT1 expression are associated with several diseases, such as facioscapulohumeral muscular dystrophy (FSHD) (23), bipolar disorder (BPAD) (24) and ALL (15). In the present review, the latest progress in understanding the role of FAT1 is discussed, with the aim of promoting interest in FAT1 as a biomarker and a potential therapeutic target for the management of several diseases.

\section{Signaling pathways and mechanisms}

FAT1 and Ena/Vasp. Ena/Vasp is an important regulator of actin dynamics. The Ena/Vasp protein family regulates the assembly of the actin cytoskeleton by antagonizing the dissociation of capping proteins and promoting actin filament branching connections, which serve a vital role in morphogenesis, axon guidance, cell migration and other processes (25-28). The role of FAT1 in the pathways necessary to determine the polarity of cells in the tissue plane has been demonstrated in Drosophila (29). The FAT1 cytoplasmic domain contains an EVH1 binding motif (4433DFPPPPEE). EVH1 binding motifs are predicted to interact with members of the Ena/Vasp protein family that contain EVH1 domains (30). Thus, FAT1 may serve a role in regulating cell migration by participating in the regulation of Ena/Vasp-dependent frontier cytoskeletal dynamics $(29,30)$. Tanoue and Takeichi (30) found that FAT1 and Ena/Vasp proteins are co-localized at the edge of the plate fat, the tip of the silk shaft and at early contact site between cells. Knockdown of FAT1 causes Vasp to no longer accumulate in these locations, and the cytoskeleton of connecting actin cannot be formed correctly (30). Additionally, it was shown that actin filaments were recruited to the junction and formed radial actin cables during the early stages of cell-cell contact in mouse cells (30). After knocking down FAT1, the connecting actin filaments were poorly arranged, and the connecting actin cytoskeleton could not be formed correctly (30). Additionally, FAT1 can promote the formation of actin stress fibers in renal epithelial cells (30). These observations indicate that FAT1 serves an important role in actin dynamics (30). Moeller et al (29) reported that in cells where FAT1 expression was knocked out, the amount of Vasp protein that accumulated at the front of cells was significantly decreased, the cells did not become polarized and the migratory ability of cells was decreased. In in vitro wound healing assays, FAT1-knockout NRK-52E cells (rat kidney epithelioid cells) exhibited abnormal lamella dynamics at the wound edge, which included an absence of lamella or abnormal lamella lipid membranes, decreased lamella size and abnormally structured lamellae, all of which resulted in delayed wound closure (31). These results indicate that FAT1 is necessary for physiological lamellipodial dynamics, and FAT1-knockout disrupts normal lamellipodial dynamics to a certain extent $(29,30)$. This may provide an explanation for the weakened cell migration in FAT1-deficient cells.

FATI and the Wnt/ $\beta$-catenin signaling pathway. The role of the Wnt/ $\beta$-catenin signaling pathway in human development and maintaining adult tissue homeostasis is well-established. Abnormalities in the Wnt signaling pathway are closely associated with the occurrence of numerous diseases, such as osteoporosis, Alzheimer's disease and pigmented diseases (32). Abnormal activation of the Wnt/ $\beta$-catenin signaling pathway is widely considered to be a promoter of tumorigenesis and cancer cell proliferation in several types of cancer (33), such as HCC (34) and colon cancer (35). The Wnt/ $\beta$-catenin signaling pathway primarily consists of three steps: Wnt signal transduction at the membrane, stable regulation of $\beta$-catenin in the cytoplasm and activation of Wnt target genes in the nucleus. FAT1 protein may affect Wnt signaling via modulation of the latter two steps (36-38).

Just as classical cadherin can bind to $\beta$-catenin and regulate its transcriptional activity, FAT1 can also bind to $\beta$-catenin and limit its translocation to the nucleus (39). This links FAT1 to the typical Wnt signaling pathway. A study by Hou et al (36) confirmed this interaction by demonstrating increased FAT1 expression following carotid artery injury in rats. The rat FAT1 cytoplasmic tail was shown to bind to $\beta$-catenin, preventing its translocation to the nucleus and thus preventing transcription of its target genes, including the known transcriptional target cyclin D1, which is a target of the typical Wnt signaling pathway (36). In addition, the results of FAT1-knockout revealed that increased FAT1 expression limited cyclin D1 expression in mouse vascular smooth muscle cells (VSMCs) (40). Cyclin D1 is a known Tcf/ $\beta$-catenin target gene, which serves a key role in the regulation of $G_{1}$ phase progression and $\mathrm{G}_{1} \mathrm{max} / \mathrm{S}$ cell cycle transition (36). Increased FAT1 expression after injury may slow down the proliferation of VSMCs by decreasing cyclin D1 expression (36). The association between FAT1 and the Wnt signaling pathway serves an important role in the overall regulation of VSMC proliferation.

Morris et al (19) revealed that endogenous FAT1 bound to $\beta$-catenin in human cells. In experiments using glioma cells and immortalized human brain astrocytes, FAT1-knockout resulted in a decrease in plasma membrane $\beta$-catenin staining, and a significant increase in nuclear $\beta$-catenin staining (19). Inactivated FAT1 expression could not sequester $\beta$-catenin at the cell membrane, thereby allowing for canonical Wnt signal transduction and tumor growth (19). Overexpression of $\beta$-catenin promoted cell proliferation and cell cycle 
Drosophila

$\mathrm{Ft}$

Ft2

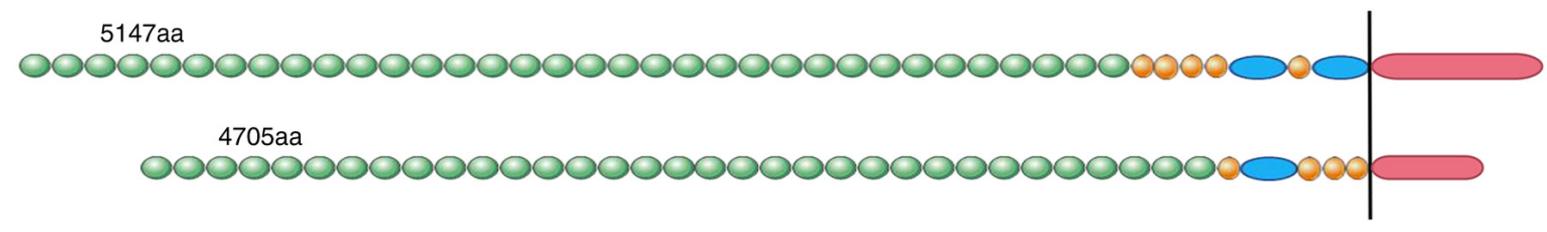

Vertebrate

FAT1

4588aa 0000000000000000000000000000000000000

FAT2

4349aa

00000000000000000000000000000000000

FAT3

00000000000000000000000000000000000000

FAT4

4981 aa

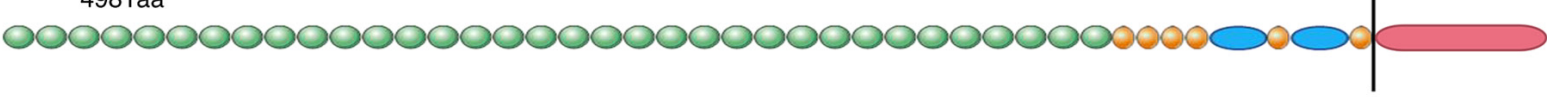

Cadherin repeat

EGF-like motif

Laminin G-like motif

Intracellular domain

Figure 1. Members of the FAT cadherin family of Drosophila and vertebrates. FAT1 and FAT4 have 34 cadherin repeats, FAT2 has 32 cadherin repeats and FAT3 has 33 cadherin repeats. Each member has its unique number and arrangement of EGF-like and laminin G-like motifs. FAT4 is considered to be homologous to Drosophila Ft, FAT1 and FAT3 are considered to be homologous to Drosophila Ft2, while FAT2 is considered phylogenetically unique. FAT, FAT atypical cadherin; aa, amino acids.

progression, and increased the incorporation of BrdU (indicative of increased proliferation), but these effects were inhibited by FAT1 (19). Knockout of CTNNB1 (encoding $\beta$-catenin) in glioblastoma multiforme cells decreased cell proliferation, cell cycle progression and BrdU incorporation. These effects were largely reversed by FAT1-knockout (19). After knocking down FAT1 in glioma cells and immortalized human astrocytes using small interfering RNAs, $\beta$-catenin-mediated transcription was significantly increased (19). Another means by which FAT1 affects the Wnt/ $\beta$-catenin signaling pathway is that the deletion of FAT1 alters gene expression and affects the expression of components of the Wnt/ $\beta$-catenin signaling pathway (19). Knockout of FAT1 mRNA resulted in consistent upregulation of multiple $\mathrm{Wnt} / \beta$-catenin target genes, including myc, cyclin D1, inhibitor of DNA binding 2, transcription factor 4, claudin and zinc finger E-box binding homeobox 1 (ZEB1) (41-43). Similar results were obtained based on analysis of data obtained from an ovarian cancer dataset from The Cancer Genome Atlas $(19,44)$. Based on the identification of 189 significantly differentially expressed genes, it was revealed that tumors with low FAT1 expression exhibited enrichment of genes associated with the Wnt/ $\beta$-catenin signaling pathway (44). These results suggest that FAT1 mutations may be a prominent cause of the dysregulation of the Wnt signaling pathway in cancer (44).

FATl and the Hippo signaling pathway. The Hippo signaling pathway, also known as the Salvador (Sav)-Wts-Hippo signaling pathway, includes three primary components: Upstream regulators, core kinase cassettes and downstream transcriptional activators $(45,46)$. The Drosophila kinase cassette includes Wts and the serine/threonine kinase Hippo, as well as its two cofactors Sav and Mob as tumor suppressors (referred to as Mats) (45). The downstream transcriptional co-activator, Yki, controls the activity of several transcription factors through subcellular localization $(45,47)$. When the core kinase cassette is activated, Yki is phosphorylated and retained in the cytoplasm, where it is eventually degraded (45). In the absence of upstream activation signals, Yki exists in a non-phosphorylated state and is transferred to the nucleus, where its transcription program is formulated, thereby promoting cell proliferation (45). The Ft mutation in the overgrowth phenotype of Drosophila is considered to exert its effects upstream of the Hippo signaling pathway, and is mediated by affecting the subcellular localization of Yki $(48,49)$. Numerous studies have demonstrated the important role of the Hippo signaling pathway in mammalian organ size and tumorigenesis (50-52). Changes in gene expression caused by inhibition of Hippo-associated proteins Yes-associated protein (YAP)/TAZ can inhibit cell proliferation, promote apoptosis and ultimately control organ size (52). Overexpression of YAP/TAZ can result in uncontrolled cell proliferation, which makes the Hippo signaling pathway one of the key pathways involved in cancer development (52). Under conditions of low cell density, YAP and TAZ (both are homologous to Drosophila $\mathrm{Yki}$ ) control the transcription program of genes that are the transcription targets of TEAD and $\operatorname{SMAD}(53,54)$. When the cell density is high, the core kinase cassette is activated; this activation prevents the nucleocytoplasmic shuttle of YAP and TAZ, and inhibits their transcriptional activity $(52,55)$. The vertebrate core kinase cassette involves Sav, large tumor suppressor $1 / 2$ and macrophage stimulating $1 / 2$, which are homologous to the Drosophila kinases Sav, Wts and Hippo, respectively $(52,54,55)$.

Some progress has been made regarding the potential association between FAT cadherin and Hippo signaling in 


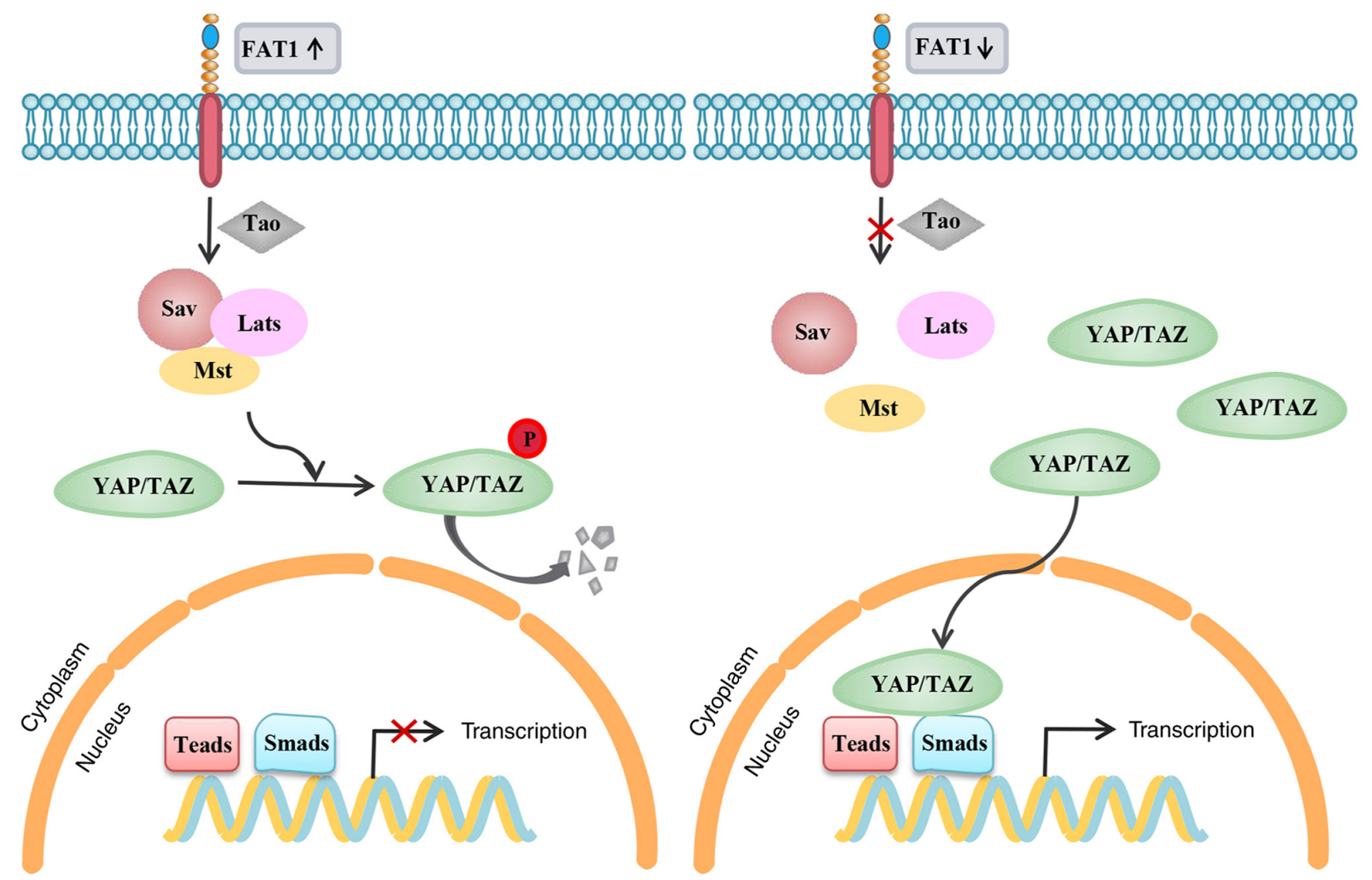

Figure 2. Association between FAT1 and Hippo signaling pathway. Schematic diagram of the FAT1 cytoplasmic tail (not drawn to scale) depicting the association between FAT1 and the Hippo signaling pathway. FAT1 induces the activation of the Hippo core kinase cassette via kinase Tao, which leads to the phosphorylation of YAP/TAZ, which is finally degraded by proteasome. In the absence of FAT1, YAP/TAZ is not phosphorylated and is transferred to the nucleus to start the transcription and upregulate target gene expression. FAT1, FAT atypical cadherin 1; p, phosphorylated; Sav, Salvador; Lats, large tumor suppressor; Mst, macrophage stimulating; YAP, Yes-associated protein.

vertebrates. Similar to Drosophila Ft, the FAT1 protein has been shown to be an upstream factor of the Hippo signaling pathway (20). FAT1 acts as an upstream regulator of TAZ, as well as an upstream regulator of YAP in the process of neuronal differentiation (56). The intracellular domain of FAT1 interacts with a multimeric Hippo signaling protein and participates in its assembly, which in turn induces the kinase Tao to activate the Hippo kinase cassette (17). This causes phosphorylation and inactivation of YAP, a transcriptional coactivator downstream of the Hippo signaling pathway, and antagonization of the function of the Hippo effector, TAZ (17). Knockout of the FAT1 gene increases the nuclear accumulation of YAP and promotes the nuclear and cytoplasmic shuttling of the transcriptional activator TAZ, thereby upregulating the transcription of the Hippo target genes connective tissue growth factor and ankyrin repeat domain 1 , which is also accompanied by an increase in the nuclear levels of SMAD2/3 (Fig. 2) (57). The role of FAT1 in modulation of upstream factors of the Hippo signaling pathway provides further evidence of its important role in development and disease.

FATl and the MAPK/ERK signaling pathway. The MAPK/ERK signaling pathway serves a role in cell proliferation, differentiation and apoptosis. Uncontrolled MAPK/ERK activity is commonly observed in tumors $(58,59)$. The MAPK/ERK signaling pathway is involved in cell migration and invasion of several types of cancer, such as multiple myeloma, lung cancer and HCC (58-60). It was revealed that FAT1 mutations in pituitary spindle cell tumor were associated with increased MAPK activity, based on the phosphorylation of ERK (p-ERK1/2), highlighting an association between FAT1 and the MAPK signaling pathway (61). Another study suggested that FAT1 may affect esophageal squamous cell carcinoma (ESCC) cell proliferation through the loss of control of the MAPK/ERK signaling pathway (21). Exogenous FAT1 expression can inhibit cell proliferation and colony formation, and inhibit cell migration and invasion, whereas FAT1-knockout exerts the opposite effects, both in vivo (FAT1-knockdown stable ESCC cells and ESCC cells with FAT1-WT overexpression were subcutaneously injected into the left or right oxter of female BALB/c-nu mice) and in vitro (ESCC cell lines) (21). Knockout of FAT1 significantly increased the levels of p-ERK1/2 in multiple esophageal cancer cells, whereas overexpression of FAT1 decreased p-ERK1/2 levels (21). When U0126, a highly selective inhibitor of ERK1/2 phosphorylation, was used to treat FAT1-knockout cells, it abolished the migratory and invasive ability of cells (21). The aforementioned studies indicate that FAT1 affects cell proliferation in a MAPK/ERK-dependent manner, at least in part. Wang et al (62) revealed that FAT1-knockout increased the mRNA expression levels of MAP3K8, MAP2K2 and MAP2K6 in esophageal squamous cell carcinoma cells, and decreased the mRNA expression levels of the MAPK inactivator dual specificity phosphatase 6 , resulting in enrichment of the MAPK signaling pathway. 


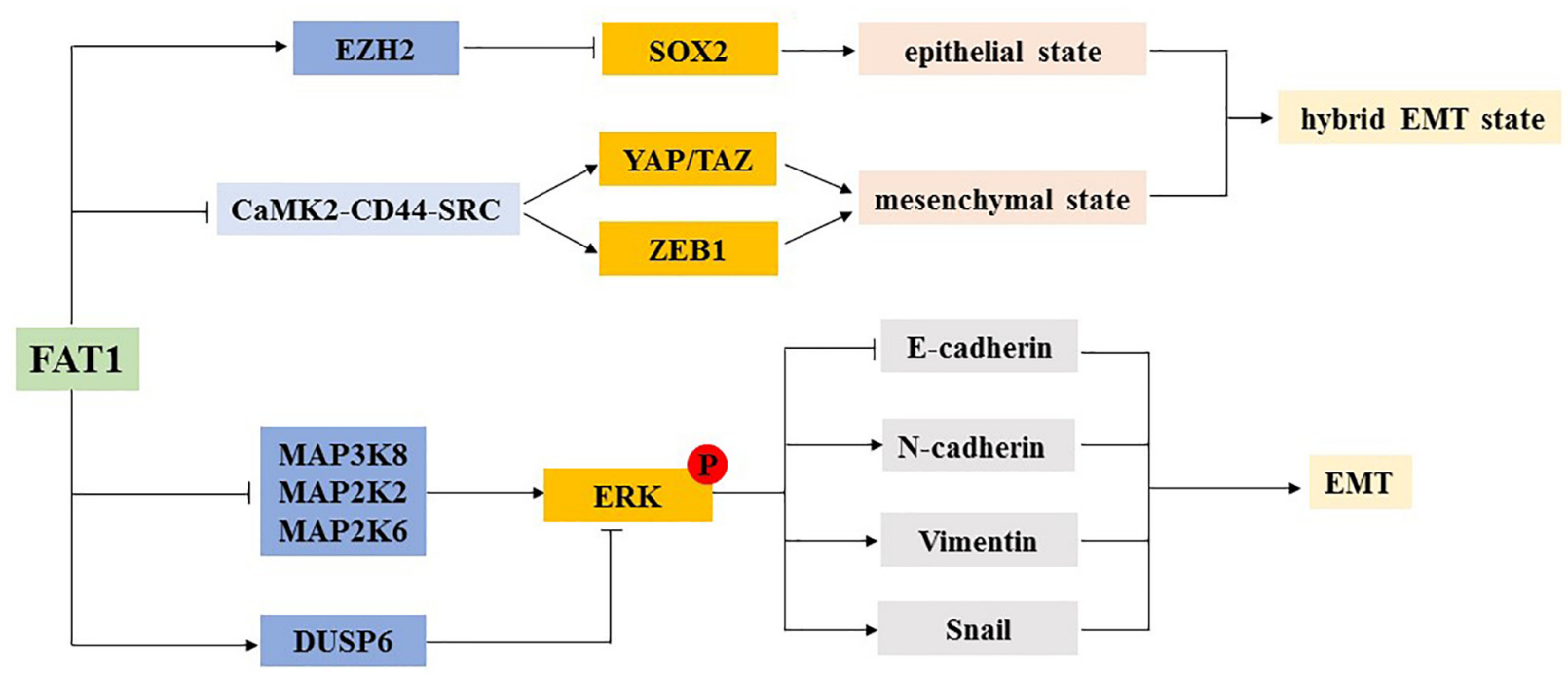

Figure 3. Association between FAT1 and EMT. FAT1 controls different transcription procedures via regulating the expression levels of SOX2 by affecting the expression levels of EZH2 and the CaMK2-CD44-SRC-YAP-ZEB1 axis, and regulates the co-expression of epithelial and mesenchymal transcription programs in cancer cells, leading to the emergence of a hybrid EMT phenotype. In addition, FAT1 regulates the expression levels of the epithelial marker E-cadherin and the mesenchymal markers N-cadherin, vimentin and Snail by affecting the phosphorylation level of ERK1/2. FAT1, FAT atypical cadherin 1; EMT, epithelial-mesenchymal transition; p, phosphorylated; ZEB1, zinc finger E-box binding homeobox 1; CaMK2, calcium/calmodulin-dependent protein kinase II; DUSP6, dual specificity phosphatase 6; EZH2, enhancer of zeste homolog 2; YAP, Yes-associated protein.

However, additional experimental evidence is required to understand how FAT1 regulates the MAPK/ERK signaling pathway.

FAT1 and EMT. EMT is a cellular biological process that promotes the migration of cancer cells. In addition, EMT is characterized by stemness, invasion and drug resistance $(21,63)$. The association between FAT1 and EMT has been confirmed in several types of cancer, including ESCC (21), HCC (64) and glioblastoma (65). After inhibiting FAT1 expression, the expression levels of the epithelial marker E-cadherin decreased significantly, whereas the expression levels of $\mathrm{N}$-cadherin, vimentin and the stromal marker Snail increased, which in turn increased cell proliferation, suggesting that FAT1 may be a key regulator of EMT (21). When FAT1-knockout cells were treated with U0126, an inhibitor of ERK1/2 phosphorylation, the regulation of E-cadherin, $\mathrm{N}$-cadherin, vimentin and Snail expression was reversed (21). These results suggest that FAT1 affects cell proliferation and EMT progression, at least in part, in a MAPK/ERK-dependent manner (21).

Recent studies have suggested that exposure to partial EMT or mixed EMT can further enhance tumor cell (such as skin squamous cell carcinoma cells and lung cancer cells) stemness, migration, invasion and drug resistance $(22,63,66)$. In mouse models of skin squamous cell carcinoma and lung cancer, it was revealed that the loss of FAT1 accelerated tumor development and malignant progression, and promoted the transformation of mixed EMT phenotype (22). This mixed EMT state has also been observed in human squamous cell carcinoma with FAT1 mutations (22). Cutaneous squamous cell carcinoma with FAT1 deletion exhibited increased stemness and spontaneous metastasis (22). In mouse and human squamous cell carcinoma, the loss of FAT1 function promotes tumor initiation, progression, invasion, stemness and metastasis by inducing the acquisition of a mixed EMT state (22). The loss of FAT1 function activates the calcium/calmodulin-dependent protein kinase II/CD44/SRC axis, and promotes the nuclear translocation of YAP1 and ZEB1 expression, thus stimulating the interstitial state (22). Additionally, the loss of FAT1 function results in inactivation of enhancer of zeste homolog 2 subunit and promotes SOX2 expression, thus maintaining an epithelial state (22). In addition, FAT1-knockout skin squamous cell carcinoma cells were significantly more resistant to the EGFR inhibitor afatinib and the MEK inhibitor trametinib (22). Thus, identifying the role of FAT1 in EMT, as well as the effects of mutations of the FAT1 gene in the process of EMT, may be of great importance in improving the prognosis and treatment of patients with cancer (Fig. 3).

\section{FAT1 in development}

Aberrant FAT1 expression or mutations affecting its function affect several signaling pathways via complex mechanisms, through which FAT1 physiologically regulates development. FAT1 expression in tissues is higher in certain vertebrates. Ponassi et al (67) identified FAT1 expression in the brain of developing and adult rats, and revealed that it was most strongly expressed in areas involved in neurogenesis. FAT1 serves a role in the early stages of neuronal cell differentiation, controls the outward growth of neurites through the Hippo signaling pathway and promotes terminal differentiation of cells by inhibiting proliferation (20). FAT1 is expressed during the development of the embryonic brain, kidney and other epithelial tissues, and similar expression patterns are observed in rats, chickens, zebrafish and other vertebrates (7). The pups of FAT1-knockout mice resulted in their death as a result of renal failure within $48 \mathrm{~h}$ (68). FAT1 mRNA expression in the gap junction between podocytes in the glomerular filtration membrane has been reported (69). Gap junctions are modified adhesive junctions with wide intercellular spaces that allow 
kidney filtration (68). FAT1 creates the necessary intercellular adhesion between podocyte protrusions, while maintaining a wider extracellular space than normally found in adhesion junctions (68). In the absence of FAT1 mRNA, the physiological orderly array of gap junctions is not present, and the podocytes become closely opposed to each other, resulting in significant renal dysfunction, which may explain the perinatal death of mice lacking FAT1 mRNA (68). Additionally, these mouse pups exhibited severe midline developmental defects, including total forebrain deformities, small eyeballs and ocular disorders, with some mice exhibiting atrophy of the ciliary muscles (68).

There is little knowledge regarding FAT1 in human tissues, but it appears to serve a more prominent role in embryonic development. Human tissue in situ hybridization revealed high levels of FAT1 mRNA transcription in the fetal epithelium (15). FAT1 is reported to be widely expressed throughout the nervous system and may control neuromuscular morphogenesis (36). Furthermore, FAT1 mRNA expression was identified in embryonic stem cells and kidney tissues (36). Although FAT1 expression is downregulated or deleted following organogenesis and terminal differentiation, there is a low level of FAT1 expressed in adult tissues, indicating that FAT1 may serve a role in the maintenance of human organs, as well as in development (70).

Cadherins are considered to be the primary medium regulating the dynamic balance of epithelial cells and may serve an important role in vascular remodeling (71). FAT1 expression in VSMCs is increased significantly following arterial injury (29). FAT1 expression is increased after vascular injury, which promotes the migration of VSMCs and inhibits their proliferation (29). Increased FAT1 expression provides directional signals and stimulates actin cytoskeleton remodeling by interacting with Ena/Vasp proteins, thus promoting the migration of VSMCs, whereas inhibition of proliferation partly depends on the decrease of nuclear accumulation of $\beta$-catenin $(29,30)$. The aforementioned studies provide an explanation for the formation of cell clusters that oppose excessive proliferation in the repair of vascular injury (36). Although FAT1 expression in human vascular diseases has not been extensively studied, the loss of negative regulation mediated by FAT1 may lead to VSMC hyperplasia syndromes, such as restenosis, graft artery disease or vein graft disease (36).

\section{FAT1 in hereditary diseases}

Homozygous frameshift mutations in FAT1 have been reported to cause the 4q-syndrome characterized by facial deformities, cutaneous syndactyly and ocular abnormalities, with or without nephropathy (72). Facial malformations primarily manifest as an elongated facial appearance, with a long philtrum and long nose (72). Eye abnormalities in patients with mutations in the FAT1 gene include ptosis, microphthalmos, retinal defects and severe amblyopia (72). The cause may be that the loss of FAT1 function impairs the adhesion and fusion between epithelial cells, leading to fissures and neural tube closure defects $(7,72)$. In addition to the eyes, the key roles of FAT1 cadherin in the cell-cell connection process is of great importance in the kidney. Loss of FAT1 function results in decreased adhesion of epithelial cells and the disappearance of podocyte foot processes, destroying the lumen formation of renal tubular epithelial cells and causing kidney disease, such as hormone resistant nephrotic syndrome and glomerulonephritis $(70,72)$.

Previous studies have revealed that FAT1 expression is downregulated in FSHD, suggesting that FAT1 may be associated with FSHD $(23,73)$. The inactivated FAT1 protein results in apolarized myoblasts, thus altering their morphology and affecting the overall shapes of certain muscle groups in the face and shoulders (74,75). Further research is required to understand the association between FAT1 and FSHD.

Results linking the FAT1 gene with BPAD have also been published. In a patient-controlled study by Blair et al (24) in Australia,FAT1 was identified as a susceptibility gene of BPAD, and single nucleotide polymorphisms (SNPs) were identified in the FAT1 region that included the binding sites of EVH1 and $\beta$-catenin. An independent study conducted in German patients (24) revealed that 9 SNPs were identified in FAT1, of which 8 were located in the haplotype region associated with BPAD discovered by Blair et al (24). However, although there are several studies highlighting a genetic component of BPAD (76-78), relatively little is known regarding its specific cause. However, FAT1 gene variants may be involved in the etiology of BPAD $(24,79)$.

\section{FAT1 in cancer}

FAT1 in hematological malignancies. As aforementioned, FAT1 was first cloned from a human T-ALL cell line, suggesting that FAT1 is expressed in tumors of the hematopoietic system (15). However, FAT1 expression is rarely expressed in normal hematopoietic systems (15). FAT1 is expressed in $60 \%$ of T-ALL, $30 \%$ of precursor B-cell ALL and $10 \%$ of acute myeloid leukemia cases, and FAT1 expression is associated with a more mature immune phenotype of leukemia $(19,80)$. Compared with patients with early T-ALL, FAT1 expression is higher in patients with thymic T-ALL and mature T-ALL (80). In addition, high FAT1 mRNA expression is associated with a poor prognosis and high recurrence rate in patients with T-ALL (81).

The FAT family members are considered tumor suppressor candidates, and the FAT1 protein is overexpressed in human hematopoietic tumors (81). Overexpression of FAT1 in T-ALL is accompanied by changes in post-translational processing, resulting in staining being primarily observed in the membrane at physiological expression levels to staining being primarily observed in the cytoplasm and nucleus when overexpressed (15). This mislocalization is due to changes in the proteolytic pathways specific to cancer cells (17). FAT1 undergoes $\mathrm{S} 1$ proteolytic treatment by proprotein convertase during the transition process through the trans-Golgi network, resulting in the expression of heterodimers on the cell surface (17). On the surface of cells expressing FAT1, FAT1 can be further cleaved by the currently unknown S2 protease that releases the extracellular domain (17). Subsequently, a further cleavage step catalyzed by $\gamma$-secretase releases the cytoplasmic tail $(7,17)$. The changes in post-translational processing and the resulting erroneous localization of FAT1 disrupt the normal downstream function and the apparent copy loss of the signal transduction pathway of FAT1 (17). 
FATl in HCC. Liver cancer was the sixth most common cancer and the third leading cause of cancer-associated death worldwide in 2018 (82). HCC represents $75-85 \%$ of primary liver cancer cases (83). The incidence of liver cancer continues to increase, and the rate of metastasis, recurrence and mortality remain high, making liver cancer a serious threat to human health $(83,84)$. For example, there were $\sim 850,000$ new liver cancer cases in 2018, and an estimated 800,000 liver cancer-associated deaths per year (85). At present, the mechanisms underlying the development of HCC have not been fully elucidated, but it is well-established that $\mathrm{HCC}$ is closely associated with liver fibrosis, and $~ 90 \%$ of HCC cases occur as a result of progression of liver cirrhosis $(86,87)$. A previous study has revealed that FAT1 expression increases during liver fibrosis and have confirmed that activated hepatic stellate cells are the source of increased FAT1 expression in diseased livers (16). This describes a novel mechanism for the occurrence of HCC. Valletta et al (16) confirmed that FAT1 expression in cancer tissues was significantly upregulated compared with in normal liver tissues by analyzing FAT1 protein expression in 112 human HCC tissues. Strong positive FAT1 expression was significantly associated with higher tumor stages and proliferation rates (16). Moreover, FAT1 expression at the mRNA and protein levels in three liver cancer cell lines (HepG2, PLC and Hep3B) was significantly upregulated compared with in normal liver cells (16). Knocking down FAT1 expression decreased the proliferation, migration and anti-apoptotic ability of HCC cells (16).

FAT1 is a tumor promoter in HCC. FAT1 promotes the migration of HCC cells by regulating the expression levels of EMT-associated genes, including Snail, vimentin and E-cadherin (64). In addition, FAT1 seems to be a relevant mediator of hypoxia and growth receptor signal transduction tumorigenic pathways in HCC. Hypoxia often occurs in tumor tissues and is a key promoter of liver cancer progression (88). Hepatocyte growth factor (HGF) also serves a key role in the occurrence of liver cancer (89). HGF-induced and hypoxia-mediated activation of hypoxia-inducible factor- $1 \alpha$ can enhance methionine adenosyltransferase (MAT)2A expression and thus enhance the activity of MATII, whereas the activity of MATI is inhibited, resulting in decreased levels of methyl donor S-Adenosyl-1-methionine (SAM) (16). Lower SAM levels lead to decreased methylation of the FAT1 promoter, thus increasing FAT1 expression (16). Demethylated chemicals can induce FAT1 expression in HCC cells (16). The use of sorafenib in HCC cells can significantly inhibit FAT1 expression (14).

FAT1 expression is closely associated with the occurrence and development of HCC. Inhibiting FAT1 expression has an inhibitory effect on the proliferation and migration of HCC cells (16). In-depth study of the mechanism of FAT1 and its association with hypoxia, HGF and related factors, such as SAM, is of great importance for the diagnosis, treatment and prognosis of HCC.

FAT1 in head and neck squamous cell carcinoma (HNSCC). HNSCC, including oral SCC, is one of the most common malignant tumors in the world, with $\sim 650,000$ new cases and 350,000 deaths each year (89). The primary risk factors for development of HNSCC are smoking and alcohol abuse (90).
It has been confirmed that mutations of tumor protein $\mathrm{p} 53$ (TP53), NOTCH family genes and PIK3CA-related elements contribute to the pathogenesis of HNSCC (91). Additionally, a previous study has revealed that human papillomavirus (HPV) is closely associated with the onset and progression of HNSCC (92). However, the role of these factors in tumors is largely unclear. Despite advances in surgery, chemotherapy and radiation therapy, the survival rate of patients with HNSCC has not improved significantly (93). Therefore, understanding the genomic changes in the carcinogenic process of HNSCC is essential for correct diagnosis and treatment.

Recently, two large-scale exome sequencing studies demonstrated that FAT1 mutations occurred frequently in patients with HNSCC $(94,95)$. FAT1 seems to be the second most mutated gene in HNSCC, second only to TP53 (92). In 29\% of HNSCC cases, patients harbor destructive FAT1 mutations, most of which are nonsense and missense mutations $(94,96)$. These mutations cause a decrease or loss of FAT1 mRNA and protein expression. Lin et al (94) revealed that in HNSCC cell lines (OECM1, HSC3, FaDu, SCC25, SAS and OC3), FAT1 mRNA and protein expression was decreased or absent compared with in normal oral mucosal epithelial cells. After FAT1-knockout in cells, the migration and invasion of cells increased significantly, suggesting that FAT1 inhibition may enhance the migration and invasiveness of HNSCC cells (94). Additionally, by analyzing the clinical data of 96 patients with HNSCC, it was revealed that the frequency of FAT1 malignant mutations in patients with lymph node metastasis was higher than in those without metastasis $(92,94)$. FAT1 gene mutations were significantly associated with positive lymphatic vascular intravasation and tumor recurrence (94). Kaplan-Meier analysis demonstrated that the disease-free survival rate of patients with laryngeal cancer with FAT1 gene mutations was significantly lower than that of patients with wild-type FAT1 (94). Martin et al (97) confirmed that the inactivating mutations of FAT1 caused YAP1 activation through the inactivation of the Hippo signaling pathway, thereby promoting HNSCC progression, indicating that FAT1 may act as a tumor suppressor in HNSCC upstream of YAP1. In addition, FAT1 deficiency may indirectly promote $\beta$-catenin activation through a mechanism downstream of YAP1 (97). There is crosstalk between the Hippo and Wnt signaling pathways; however, the exact mechanism of how FAT1 potentially regulates both the Hippo and Wnt signaling pathways is unclear. The exact signaling pathway is likely to be cell- or tissue-specific. Therefore, the role of FAT1 expression in HNSCC should not be underestimated. Frequent changes in FAT1 may lead to defects in Hippo signaling and uninhibited YAP1 activity. Molecular therapy targeting FAT1 or its downstream targets may become an attractive precision therapeutic for the treatment of HNSCC and other malignant tumors in which FAT1 is mutated.

FAT1 in ESCC. Esophageal cancer is one of the most invasive tumors (98). Most global esophageal cancer cases ( $70 \%$ ) occur in China (99), and the majority of cases are ESCC $(98,100)$. The occurrence of ESCC is associated with several factors. Unlike Western regions, such as Europe and the United States, smoking and drinking are not the primary risk factors for ESCC in China. The risk factors for ESCC in China include burnt food, sauerkraut, nitrosamines and moldy 
foods $(101,102)$. Although progress has been made in ESCC treatment, the 5-year overall survival rate in patients remains low, ranging between 15\% and 25\% (98). Therefore, the identification of new predictive biomarkers is important for the development of novel therapeutics for management of ESCC.

A previous study has revealed that FAT1 is one of the important mutant genes in ESCC (103). FAT1 expression in ESCC tissues is significantly decreased compared with in normal esophageal tissues (103). Hu et al (21) compared 76 primary esophageal tumor tissues with matched adjacent non-tumor tissues, and revealed that FAT1 expression in non-tumor tissues was significantly higher compared with in tumor tissues. Additionally, FAT1-knockout increased the proliferation, shortened the mitotic cycle and significantly promoted the migration and invasion of ESCC cells (21). On the other hand, overexpression of FAT1 inhibited cell proliferation, colony formation, cell migration and invasion (62). Furthermore, following FAT1-knockout, the expression levels of the epithelial marker E-cadherin were significantly decreased, while the expression levels of mesenchymal markers N-cadherin, vimentin and Snail were significantly increased, and this was dependent on the MAPK/ERK signaling pathway (21). The overexpression of FAT1 resulted in the opposite trend, and these changes were abrogated by treatment with the MEK specific inhibitor U0126 (21). Hou et al (36) analyzed the changes of FAT1 expression in ESCC and its effect on the proliferation, migration and invasion of esophageal cancer cells, and the results were consistent with those of $\mathrm{Hu}$ et al (21). However, Hou et al (36) revealed that FAT1 was transcriptionally regulated by E2F transcription factor 1 (E2F1); E2F1 activated the transcription of FAT1 in ESCC cells by binding to the FAT1 promoter, although the exact mechanism remains unclear.

In general, FAT1 serves a role in the growth of ESCC and the occurrence of EMT. Inhibition of FAT1, at least partially promotes the occurrence and development of ESCC by increasing the activity of the MAPK/ERK signaling pathway, thereby exhibiting a tumor suppressor effect in ESCC (21). This is of great importance for understanding the occurrence and development of ESCC.

FAT1 in breast cancer. Between 2012 and 2016, the breast cancer incidence rate increased by $0.3 \%$ per year worldwide, and the age of incidence is getting lower, posing a huge threat for women (104). The vast majority of breast cancer cases are invasive ductal carcinoma (IDC), accounting for $\sim 80 \%$ of cases (105). Abnormal hormone levels and long-term environmental stimulation are considered high risk factors for breast cancer (106). Early diagnosis of breast cancer is difficult as it is usually asymptomatic during the early stages, and most patients are usually diagnosed at an advanced stage, leading to a higher mortality rate $(105,106)$.

Wang et al (107) used immunohistochemical analysis to detect FAT1 and $\beta$-catenin protein expression in ductal carcinoma in situ (DCIS) and IDC, revealing that, compared with in DCIS, the expression levels of FAT1 and $\beta$-catenin in IDC were significantly decreased. Additionally, loss of FAT1 expression was associated with higher histological grade and worse lymph node status in human breast cancer $(107,108)$. In addition,FAT1 and $\beta$-catenin expression in DCIS and IDC were positively correlated with each other. FAT1(-), $\beta$-catenin(-) or FAT1(-)/ $\beta$-catenin(-) suggested a worse disease-free survival rate and prognosis in patients with breast cancer (107). The loss of FAT1 and $\beta$-catenin was associated with breast cancer progression, aggressive behavior and a poor prognosis, but the underlying mechanisms between the low expression levels of FAT1 in breast cancer and the Wnt/ $\beta$-catenin signaling pathway are incompletely understood (107). FAT1 alone or in combination with $\beta$-catenin may be a valuable biomarker for predicting the prognosis of patients with breast cancer (107).

Notable progress has been made regarding the role of FAT1 in breast cancer drug resistance. Cyclin-dependent kinase 4/6 (CDK4/6) inhibitors (CDK4/6i) have been demonstrated to be effective in treating numerous types of cancer, such as breast cancer (107), melanoma (109) and pancreatic cancer (110). However, the incidence of drug resistance in cancer is increasing, and the understanding of the mechanisms involved remains limited. Li et al (111) analyzed 348 cases of patients with estrogen receptor-positive breast cancer treated with CDK4/6i and revealed that FAT1 loss-of-function mutations were associated with drug resistance. In vivo and in vitro experiments demonstrated that FAT1 deletion promoted CDK4/6i resistance through the Hippo signaling pathway (111). Loss of FAT1 caused YAP and TAZ transcription factors to accumulate on the CDK6 promoter, leading to a significant increase in CDK6, whereas overexpression of CDK6 decreased drug sensitivity (111). These findings suggest that downregulated FAT1 expression may be a means of countering CDK4/6i (111). This provides a novel avenue for the study of tumor drug resistance.

FAT1 in other types of cancer. The specific role of FAT1 in tumorigenesis and development is still being studied. Research on the role of FAT1 in human cancer has revealed that FAT1 can function as both an oncogene and a tumor suppressor gene, dependent on the type of cancer. In addition to its role in HCC, FAT1 exhibits a carcinogenic role in gastric cancer (GC). FAT1 expression is upregulated in patients with GC and is associated with cell migration and invasion, as well as with a poor prognosis (112).

The deletion of FAT1 has been reported in a variety of tumors. In addition to the aforementioned HNSCC, ESCC and breast cancer, FAT1 loss has been observed in glioblastoma multiforme (50), cervical cancer (24), Hodgkin's disease (113), cholangiocarcinoma (114), primary bladder cancer (115), lung cancer (116) and colorectal cancer (117).

After overexpressing the FAT1 gene in a glioblastoma multiforme cell line, cell cycle progression was arrested at the $\mathrm{G}_{1}-\mathrm{S}$ checkpoint, and high FAT1 expression significantly increased the proportion of cells in $\mathrm{G}_{1}$ phase, while decreasing the proportion of cells in S phase (19). Chen et al (118) revealed that the overexpression of FAT1 in cervical cancer promotes E-cadherin protein expression and significantly inhibits the proliferation, invasion and migration of cervical cancer cells, whereas the knockdown of FAT1 promotes EMT and tumor progression (118). Yu and Li (114) suggested that FAT1 may be a potential prognostic marker for childhood medulloblastoma. The proliferation rate of medulloblastoma cells in which FAT1 expression was silenced was significantly increased (114). Low FAT1 expression was associated with a poor prognosis of childhood medulloblastoma, and the survival time of children with 
Table I. Functions of FAT atypical cadherin 1 in various diseases.

\begin{tabular}{|c|c|c|c|c|}
\hline Disease & Expression & $\begin{array}{l}\text { Protein interaction/ } \\
\text { signaling pathways }\end{array}$ & Function & Refs. \\
\hline 4q-syndrome & Downregulated & Unknown & Cell adhesion & $(65)$ \\
\hline $\begin{array}{l}\text { Facioscapulohumeral } \\
\text { muscular dystrophy }\end{array}$ & Downregulated & Unknown & Cell polarity & $(68,69)$ \\
\hline Bipolar disorder & Downregulated & $\beta$-catenin & Unknown & $(70,71)$ \\
\hline $\begin{array}{l}\text { Acute lymphoblastic } \\
\text { leukemia and acute } \\
\text { myeloid leukemia }\end{array}$ & Upregulated & Unknown & Unknown & $(72,73)$ \\
\hline $\begin{array}{l}\text { Hepatocellular } \\
\text { carcinoma }\end{array}$ & Upregulated & Unknown & Cell proliferation, migration, invasion and EMT & $(14,76-78)$ \\
\hline Gastric cancer & Upregulated & Unknown & Cell migration and invasion & $(100)$ \\
\hline $\begin{array}{l}\text { Head and neck } \\
\text { squamous cell carcinoma }\end{array}$ & Downregulated & $\begin{array}{l}\text { Hippo and } \\
\text { Wnt/ } \beta \text {-catenin } \\
\text { signaling } \\
\text { pathways }\end{array}$ & Cell migration and invasion & $(84,85,87)$ \\
\hline $\begin{array}{l}\text { Esophageal squamous } \\
\text { cell carcinoma }\end{array}$ & Downregulated & $\begin{array}{l}\text { MAPK/ERK } \\
\text { signaling } \\
\text { pathway }\end{array}$ & Cell proliferation, migration, invasion and EMT & $(20,31,57)$ \\
\hline Breast cancer & Downregulated & $\begin{array}{l}\text { Hippo and } \\
\text { Wnt/ } \beta \text {-catenin } \\
\text { signaling } \\
\text { pathways }\end{array}$ & Cell invasion & $(96,99)$ \\
\hline Cervical cancer & Downregulated & Unknown & Cell proliferation, migration, invasion and EMT & $(106)$ \\
\hline
\end{tabular}

EMT, epithelial-mesenchymal transition.

medulloblastoma with upregulated FAT1 protein expression was relatively longer compared with those with downregulated FAT1 protein expression (114) (Table I).

\section{Therapeutic targeting of FAT1}

As aforementioned, an increasing number of studies have confirmed that FAT1 serves an important role in tumors. Therefore, exploring the therapeutic strategies targeting FAT1 may be of great importance in the management of several types of cancer, particularly in patients with FAT1 mutations. Verteporfin (VP), a drug used to treat macular degeneration, has been shown to inhibit the proliferation of a variety of GC cell lines $(112,119)$. In GC cell lines treated with VP, FAT1 expression is significantly decreased (112). The proliferative, migratory and invasive abilities of GC cells treated with VP are also significantly decreased, consistent with those of cells in which FAT1 expression is knocked down (112). However, the specific mechanisms remain unclear. When FAT1 exerts a carcinogenic effect, targeting FAT1 may be an effective method for the treatment of cancer, such as in patients with GC (112). The notion of targeting FAT1 may also be relevant to HCC. Xu et al (120) revealed that low microRNA (miR)-223-3p expression in HCC cells was negatively correlated with FAT1 protein expression. Further experiments confirmed that there was a targeted regulatory association between miR-223-3p and FAT1; miR-223-3p downregulated FAT1 expression and inhibited the proliferation, migration, invasion and EMT of HCC cells by targeting FAT1 (120). However, the in-depth molecular mechanisms require further elucidation.

Fan et al (121) examined a novel method of targeted therapy of FAT1 by developing an anti-FAT1 monoclonal antibody (clone mAb198.3) that specifically recognized FAT1. The mAb198.3 clone revealed that FAT1 was expressed in $79 \%$ of colon adenocarcinoma cases, but its expression was negative or very low in most normal tissues (121). mAb198.3 was conjugated to a skeleton of gold nanoparticles to form active targeting gold nanoparticles with high payload properties (121). The coupling of mAb198.3 with gold nanoparticles can bring particles into tumor cells more effectively, but rarely into normal cells (121). In addition, this active targeted drug delivery system has high capacity for drug loading and has great potential for cancer treatment (121).

\section{Conclusions and perspectives}

FAT1 cadherin influences the Wnt, Hippo and MAPK/ERK signaling pathways, as well as EMT, and provides novel avenues for studying the role of FAT1 in physiological development and pathogenesis. In cancer, FAT1 appears to act as an oncogenic or tumor-suppressive molecule depending on the type of tumor (122). However, due to the large size of the FAT1 cadherin, there are numerous restrictions on molecular manipulation. Therefore, the understanding of FAT1 remains incomplete, more research is required to reveal the expression 
and role of FAT1 in different types of tumor and studies on the association between FAT1 and Ena/Vasp protein, as well as the MAPK/ERK signaling pathway, remain limited. Several key issues remain to be resolved, including which upstream signals of FAT1 trigger the Wnt, Hippo and MAPK/ERK signaling pathways, which receptors detect these signals, how the 34 cadherin repeats regulate intercellular contacts, whether FAT1 is primarily an adhesion molecule or a signaling protein, and how the association between these two functions is coordinated. In addition, the transcription factors and target genes that mediate FAT1 function, as well as the molecular mechanisms underlying the dysregulated FAT1 expression, remain to be identified.

In the present review, the effects of FAT1 on cell proliferation, polarization, migration and invasion via modulation of several signaling pathways and protein interactions were discussed. Improving the understanding of the role of FAT1 in certain diseases may highlight novel therapeutic targets for diagnosis and/or treatment.

\section{Acknowledgements}

Not applicable.

\section{Funding}

The present study was supported by a grant from The National Natural Science Foundation of China (grant no. 81472449).

\section{Availability of data and materials}

Not applicable.

\section{Authors' contributions}

XL conceived the presented idea and supervised the project. $\mathrm{ZP}$ and $\mathrm{YG}$ collected all the references and data. ZP wrote the manuscript. ZP and XL were responsible for confirming the authenticity of the data. All authors discussed, contributed towards, read and approved the final manuscript.

\section{Ethics approval and consent to participate}

Not applicable.

\section{Patient consent for publication}

Not applicable.

\section{Competing interests}

The authors declare that they have no competing interests.

\section{References}

1. Haugan K, Marcussen N, Kjølbye A, Nielsen M, Hennan J and Petersen J: Treatment with the gap junction modifier rotigaptide (ZP123) reduces infarct size in rats with chronic myocardial infarction. J Cardiovasc Pharmacol 47: 236-242, 2006.

2. Tsuchida S, Arai Y, Kishida T, Takahashi KA,Honjo K, Terauchi R, Inoue H, Oda R, Mazda O and Kubo T: Silencing the expression of connexin 43 decreases inflammation and joint destruction in experimental arthritis. J Orthop Res 31: 525-530, 2013.
3. El-Bahrawy M, Talbot I, Poulsom R, Jeffery R and Alison M: The expression of E-cadherin and catenins in colorectal tumours from familial adenomatous polyposis patients. J Pathol 198: 69-76, 2002.

4. Nollet F, Kools P and van Roy F: Phylogenetic analysis of the cadherin superfamily allows identification of six major subfamilies besides several solitary members. J Mol Biol 299: 551-572, 2000.

5. Tanoue T and Takeichi M: New insights into Fat cadherins. J Cell Sci 118: 2347-2353, 2005.

6. Bryant PJ, Huettner B, Held LI Jr, Ryerse J and Szidonya J: Mutations at the fat locus interfere with cell proliferation control and epithelial morphogenesis in Drosophila. Dev Biol 129: 541-554, 1988.

7. Sadeqzadeh E, de Bock C and Thorne R: Sleeping giants: Emerging roles for the fat cadherins in health and disease. Med Res Rev 34: 190-221, 2014.

8. Bennett $\mathrm{F}$ and Harvey K: Fat cadherin modulates organ size in Drosophila via the Salvador/Warts/Hippo signaling pathway. Curr Biol 16: 2101-2110, 2006.

9. Silva E, Tsatskis Y, Gardano L, Tapon N and McNeill H: The tumor-suppressor gene fat controls tissue growth upstream of expanded in the hippo signaling pathway. Curr Biol 16: 2081-2089, 2006.

10. Oh $\mathrm{H}$ and Irvine $\mathrm{K}$ : In vivo regulation of Yorkie phosphorylation and localization. Development 135: 1081-1088, 2008.

11. Yang C, Axelrod J and Simon M: Regulation of Frizzled by fat-like cadherins during planar polarity signaling in the Drosophila compound eye. Cell 108: 675-688, 2002.

12. Hill E, Broadbent I, Chothia $C$ and Pettitt J: Cadherin superfamily proteins in caenorhabditis elegans and Drosophila melanogaster. J Mol Biol 305: 1011-1024, 2001.

13. Down M, Power M, Smith SI, Ralston K, Spanevello M, Burns GF and Boyd AW: Cloning and expression of the large zebrafish protocadherin gene, Fat. Gene Expr Patterns 5: 483-490, 2005.

14. Zhang X, Liu J, Liang X, Chen J, Hong J, Li L, He Q and Cai X: History and progression of Fat cadherins in health and disease. Onco Targets Ther 9: 7337-7343, 2016.

15. Dunne J, Hanby AM, Poulsom R, Jones TA, Sheer D, Chin WG, Da SM,Zhao Q, Beverley PC and Owen MJ: Molecular cloning and tissue expression of FAT, the human homologue of the Drosophila fat gene that is located on chromosome 4q34-q35 and encodes a putative adhesion molecule. Genomics 30: 207-223, 1995.

16. Valletta D, Czech B, Spruss T, Ikenberg K, Wild P, Hartmann A, Weiss TS, Oefner PJ, Müller M, Bosserhoff AK and Hellerbrand C: Regulation and function of the atypical cadherin FAT1 in hepatocellular carcinoma. Carcinogenesis 35: 1407-1415, 2014.

17. Sadeqzadeh E, de Bock CE, Zhang XD, Shipman KL, Scott NM, Song C, Yeadon T, Oliveira CS, Jin B, Hersey P, et al: Dual processing of FAT1 cadherin protein by human melanoma cells generates distinct protein products. J Biol Chem 286: 28181-28191, 2011.

18. Schreiner D, Müller K and Hofer H: The intracellular domain of the human protocadherin hFat1 interacts with Homer signalling scaffolding proteins. FEBS Lett 580: 5295-5300, 2006.

19. Morris LGT, Kaufman AM, Gong Y, Ramaswami D, Walsh LA, Turcan S, Eng S, Kannan K, Zou Y, Peng L, et al: Recurrent somatic mutation of FAT1 in multiple human cancers leads to aberrant Wnt activation. Nat Genet 45: 253-261, 2013.

20. Ahmed AF, de Bock CE, Lincz LF, Pundavela J, Zouikr I, Sontag E, Hondermarck H and Thorne RF: FAT1 cadherin acts upstream of Hippo signalling through TAZ to regulate neuronal differentiation. Cell Mol Life Sci 72: 4653-4669, 2015.

21. Hu X, Zhai Y, Kong P, Cui H, Yan T, Yang J, Qian Y, Ma Y, Wang F, Li H, et al: FAT1 prevents epithelial mesenchymal transition (EMT) via MAPK/ERK signaling pathway in esophageal squamous cell cancer. Cancer Lett 397: 83-93, 2017.

22. Pastushenko I, Mauri F, Song Y, de Cock F, Meeusen B, Swedlund B, Impens F, Van Haver D, Opitz M, Thery M, et al: Fat1 deletion promotes hybrid EMT state, tumour stemness and metastasis. Nature 589: 448-455, 2021.

23. Mariot V, Roche S, Hourdé C, Portilho D, Sacconi S, Puppo F, Duguez S, Rameau P, Caruso N, Delezoide AL, et al: Correlation between low FAT1 expression and early affected muscle in facioscapulohumeral muscular dystrophy. Ann Neurol 78: 387-400, 2015.

24. Blair IP, Chetcuti AF, Badenhop RF, Scimone A, Moses MJ, Adams LJ, Craddock N, Green E, Kirov G, Owen MJ, et al: Positional cloning, association analysis and expression studies provide convergent evidence that the cadherin gene FAT contains a bipolar disorder susceptibility allele. Mol Psychiatry 11: 372-383, 2006.

25. Krause M, Bear J, Loureiro J and Gertler F: The Ena/VASP enigma. J Cell Sci 115: 4721-4726, 2002. 
26. Krause M, Leslie JD, Stewart M, Lafuente EM, Valderrama F, Jagannathan R, Strasser GA, Rubinson DA, Liu H, Way M, et al: Lamellipodin, an Ena/VASP ligand, is implicated in the regulation of lamellipodial dynamics. Dev Cell 7: 571-583, 2004.

27. Lafuente EM, van Puijenbroek AFL, Krause M, Carman CV, Freeman GJ, Berezovskaya A, Constantine E, Springer TA, Gertler FB and Boussiotis VA: RIAM, an Ena/VASP and profilin ligand, interacts with Rap1-GTP and mediates Rap1-induced adhesion. Dev Cell 7: 585-595, 2004.

28. Renfranz P and Beckerle M: Doing (F/L)PPPPs: EVH1 domains and their proline-rich partners in cell polarity and migration. Curr Opin Cell Biol 14: 88-103, 2002

29. Moeller MJ, Soofi A, Braun GS, Li X, Watzl C, Kriz W and Holzman LB: Protocadherin FAT1 binds Ena/VASP proteins and is necessary for actin dynamics and cell polarization. EMBO J 23: 3769-3779, 2004.

30. Tanoue $\mathrm{T}$ and Takeichi M: Mammalian Fat1 cadherin regulates actin dynamics and cell-cell contact. J Cell Biol 165: 517-528, 2004.

31. Nobes CD and Hall A: Rho GTPases control polarity, protrusion, and adhesion during cell movement. J Cell Biol 144: 1235-1244, 1999.

32. Huang P, Yan R, Zhang X, Wang L, Ke X and Qu Y: Activating Wnt/ $\beta$-catenin signaling pathway for disease therapy: Challenges and opportunities. Pharmacol Ther 196: 79-90, 2019.

33. Nusse R and Clevers $H$ : Wnt/ $\beta$-catenin signaling, disease, and emerging therapeutic modalities. Cell 169: 985-999, 2017.

34. Perugorria MJ, Olaizola P, Labiano I, Esparza-Baquer A Marzioni M, Marin JJG, Bujanda L and Banales JM: Wnt- $\beta$-catenin signalling in liver development, health and disease. Nat Rev Gastroenterol Hepatol 16: 121-136, 2019.

35. Morin PJ, Sparks AB, Korinek V, Barker N, Clevers H Vogelstein B and Kinzler KW: Activation of beta-catenin-Tcf signaling in colon cancer by mutations in beta-catenin or APC. Science 275: 1787-1790, 1997.

36. Hou R, Liu L, Anees S, Hiroyasu S and Sibinga NES: The Fat1 cadherin integrates vascular smooth muscle cell growth and migration signals. J Cell Biol 173: 417-429, 2006.

37. Clevers $\mathrm{H}$ : Wnt/beta-catenin signaling in development and disease. Cell 127: 469-480, 2006.

38. Clevers $\mathrm{H}$ and Nusse $\mathrm{R}$ : Wnt/ $\beta$-catenin signaling and disease. Cell 149: 1192-1205, 2012.

39. Kaplan D, Meigs T and Casey P: Distinct regions of the cadherin cytoplasmic domain are essential for functional interaction with Galpha 12 and beta-catenin. J Biol Chem 276: 44037-44043, 2001.

40. Tetsu $\mathrm{O}$ and McCormick F: Beta-catenin regulates expression of cyclin D1 in colon carcinoma cells. Nature 398: 422-426, 1999.

41. Rockman SP, Currie SA, Ciavarella M, Vincan E, Dow C, Thomas RJ and Phillips WA: Id2 is a target of the beta-catenin/T cell factor pathway in colon carcinoma. J Biol Chem 276 45113-45119, 2001.

42. Kolligs FT, Nieman MT, Winer I, Hu G, Van Mater D, Feng Y, Smith IM, Wu R, Zhai Y, Cho KR and Fearon ER: ITF-2, a downstream target of the Wnt/TCF pathway, is activated in human cancers with beta-catenin defects and promotes neoplastic transformation. Cancer Cell 1: 145-155, 2002.

43. He TC, Sparks AB, Rago C, Hermeking H, Zawel L, da Costa LT, Morin PJ, Vogelstein B and Kinzler KW: Identification of c-MYC as a target of the APC pathway. Science 281: 1509-1512, 1998.

44. Cancer Genome Atlas Research Network: Integrated genomic analyses of ovarian carcinoma. Nature 474: 609-615, 2011.

45. Staley B and Irvine K: Hippo signaling in Drosophila: Recent advances and insights. Dev Dyn 241: 3-15, 2012.

46. Pan D: The hippo signaling pathway in development and cancer. Dev Cell 19: 491-505, 2010

47. $\mathrm{Oh} \mathrm{H}$ and Irvine $\mathrm{K}$ : Yorkie: The final destination of Hippo signaling. Trends Cell Biol 20: 410-417, 2010.

48. Wei X, Shimizu T and Lai Z: Mob as tumor suppressor is activated by Hippo kinase for growth inhibition in Drosophila. EMBO J 26: 1772-1781, 2007.

49. McCartney BM, Kulikauskas RM, LaJeunesse DR and Fehon RG: The neurofibromatosis-2 homologue, Merlin, and the tumor suppressor expanded function together in Drosophila to regulate cell proliferation and differentiation. Development 127: 1315-1324, 2000.

50. Camargo FD, Gokhale S, Johnnidis JB, Fu D, Bell GW, Jaenisch R and Brummelkamp TR: YAP1 increases organ size and expands undifferentiated progenitor cells. Curr Biol 17: 2054-2060, 2007
51. Dong J, Feldmann G, Huang J, Wu S, Zhang N, Comerford SA, Gayyed MF, Anders RA, Maitra A and Pan D: Elucidation of a universal size-control mechanism in Drosophila and mammals. Cell 130: 1120-1133, 2007.

52. Zhao B, Li L, Lei Q and Guan K: The Hippo-YAP pathway in organ size control and tumorigenesis: An updated version. Genes Dev 24: 862-874, 2010.

53. Beyer TA, Weiss A, Khomchuk Y, Huang K, Ogunjimi AA Varelas $X$ and Wrana JL: Switch enhancers interpret TGF- $\beta$ and Hippo signaling to control cell fate in human embryonic stem cells. Cell Rep 5: 1611-1624, 2013.

54. Wrighton K, Dai F and Feng X: A new kid on the TGFbeta block: TAZ controls Smad nucleocytoplasmic shuttling. Dev Cell 15: $8-10,2008$

55. Nishioka N, Inoue KI, Adachi K, Kiyonari H, Ota M, Ralston A, Yabuta N, Hirahara S, Stephenson RO, Ogonuki N, et al: The Hippo signaling pathway components Lats and Yap pattern Tead4 activity to distinguish mouse trophectoderm from inner cell mass. Dev Cell 16: 398-410, 2009.

56. Ahmed A, de Bock C, Sontag E, Hondermarck H, Lincz L and Thorne R: FAT1 cadherin controls neuritogenesis during NTera 2 cell differentiation. Biochem Biophys Res Commun 514: 625-631, 2019.

57. Skouloudaki K, Puetz M, Simons M, Courbard JR, Boehlke C, Hartleben B, Engel C, Moeller MJ, Englert C, Bollig F, et al: Scribble participates in Hippo signaling and is required for normal zebrafish pronephros development. Proc Natl Acad Sci USA 106: 8579-8584, 2009.

58. Ye CY, Zheng CP, Ying WW and Weng SS: Up-regulation of microRNA-497 inhibits the proliferation, migration and invasion but increases the apoptosis of multiple myeloma cells through the MAPK/ERK signaling pathway by targeting Raf-1. Cell Cycle 17: 2666-2683, 2018.

59. Yan $\mathrm{P}$, Zhu H, Yin L, Wang L, Xie P, Ye J, Jiang X and He X: Integrin $\alpha v \beta 6$ promotes lung cancer proliferation and metastasis through upregulation of IL-8-mediated MAPK/ERK signaling. Transl Oncol 11: 619-627, 2018.

60. Wang WM, Xu Y, Wang YH, Sun HX, Sun YF, He YF, Zhu QF, $\mathrm{Hu} \mathrm{B}$, Zhang X, Xia JL, et al: HOXB7 promotes tumor progression via bFGF-induced activation of MAPK/ERK pathway and indicated poor prognosis in hepatocellular carcinoma. Oncotarget 8: 47121-47135, 2017.

61. Miller MB, Bi WL, Ramkissoon LA, Kang YJ, Abedalthagafi M, Knoff DS, Agarwalla PK, Wen PY, Reardon DA, Alexander BM, et al: MAPK activation and HRAS mutation identified in pituitary spindle cell oncocytoma. Oncotarget 7: 37054-37063, 2016.

62. Wang Y, Wang G, Ma Y, Teng J, Wang Y, Cui Y, Dong Y, Shao S, Zhan Q and Liu X: FAT1, a direct transcriptional target of E2F1, suppresses cell proliferation, migration and invasion in esophageal squamous cell carcinoma. Chin J Cancer Res 31: 609-619, 2019.

63. Saxena K, Jolly M and Balamurugan K: Hypoxia, partial EMT and collective migration: Emerging culprits in metastasis. Transl Oncol 13: 100845, 2020

64. Meng P, Zhang YF, Zhang W, Chen X, Xu T, Hu S, Liang X, Feng M, Yang X and Ho M: Identification of the atypical cadherin FAT1 as a novel glypican-3 interacting protein in liver cancer cells. Sci Rep 11: 40, 2021.

65. Srivastava C, Irshad K, Dikshit B, Chattopadhyay P, Sarkar C, Gupta DK, Sinha S and Chosdol K: FAT1 modulates EMT and stemness genes expression in hypoxic glioblastoma. Int J Cancer 142: 805-812, 2018

66. Pastushenko I, Brisebarre A, Sifrim A, Fioramonti M, Revenco T, Boumahdi S, Van Keymeulen A, Brown D, Moers V, Lemaire $\mathrm{S}$, et al: Identification of the tumour transition states occurring during EMT. Nature 556: 463-468, 2018.

67. Ponassi M, Jacques TS, Ciani L and ffrench Constant C: Expression of the rat homologue of the Drosophila fat tumour suppressor gene. Mech Dev 80: 207-212, 1999.

68. Ciani L, Patel A, Allen N and ffrench-Constant C: Mice lacking the giant protocadherin mFAT1 exhibit renal slit junction abnormalities and a partially penetrant cyclopia and anophthalmia phenotype. Mol Cell Biol 23: 3575-3582, 2003.

69. Inoue T, Yaoita E, Kurihara H, Shimizu F, Sakai T, Kobayashi T, Ohshiro K, Kawachi H, Okada H, Suzuki H, et al: FAT is a component of glomerular slit diaphragms. Kidney Int 59: 1003-1012, 2001

70. Yaoita E, Kurihara H, Yoshida Y, Inoue T, Matsuki A, Sakai T and Yamamoto T: Role of Fat1 in cell-cell contact formation of podocytes in puromycin aminonucleoside nephrosis and neonatal kidney. Kidney Int 68: 542-551, 2005. 
71. Uglow EB, Slater S, Sala-Newby GB, Aguilera-Garcia CM, Angelini GD, Newby AC and George SJ: Dismantling of cadherin-mediated cell-cell contacts modulates smooth muscle cell proliferation. Circ Res 92: 1314-1321, 2003.

72. Lahrouchi N, George A, Ratbi I, Schneider R, Elalaoui SC, Moosa S, Bharti S, Sharma R, Abu-Asab M, Onojafe F et al: Homozygous frameshift mutations in FAT1 cause a syndrome characterized by colobomatous-microphthalmia, ptosis, nephropathy and syndactyly. Nat Commun 10: 1180, 2019.

73. Puppo F, Dionnet E, Gaillard MC, Gaildrat P, Castro C, Vovan C, Bertaux K, Bernard R, Attarian S, Goto K, et al: Identification of variants in the 4q35 gene FAT1 in patients with a facioscapulohumeral dystrophy-like phenotype. Hum Mutat 36: 443-453, 2015.

74. Park HJ, Lee W, Kim SH, Lee JH, Shin HY, Kim SM, Park KD, Lee JH and Choi YC: FAT1 gene alteration in facioscapulohumeral muscular dystrophy type 1 . Yonsei Med J 59: 337-340, 2018

75. Caruso N, Herberth B, Bartoli M, Puppo F, Dumonceaux J, Zimmermann A, Denadai S, Lebossé M, Roche S, Geng L, et al: Deregulation of the protocadherin gene FAT1 alters muscle shapes: implications for the pathogenesis of facioscapulohumeral dystrophy. PLoS Genet 9: e1003550, 2013.

76. Stahl EA, Breen G, Forstner AJ, McQuillin A, Ripke S, Trubetskoy V, Mattheisen M, Wang Y, Coleman JRI, Gaspar HA, et al: Genome-wide association study identifies 30 loci associated with bipolar disorder. Nat Genet 51: 793-803, 2019.

77. Bipolar Disorder and Schizophrenia Working Group of the Psychiatric Genomics Consortium. Electronic address: douglas. ruderfer@vanderbilt.edu; Bipolar Disorder and Schizophrenia Working Group of the Psychiatric Genomics Consortium: Genomic dissection of bipolar disorder and schizophrenia, including 28 subphenotypes. Cell 173: 1705-1715.e1716, 2018.

78. Psychiatric GWAS Consortium Bipolar Disorder Working Group: Large-scale genome-wide association analysis of bipolar disorder identifies a new susceptibility locus near ODZ4. Nat Genet 43: 977-983, 2011.

79. Abou Jamra R, Becker T, Georgi A, Feulner T, Schumacher J, Stromaier J, Schirmbeck F, Schulze TG, Propping P, Rietschel M, et al: Genetic variation of the FAT gene at 4q35 is associated with bipolar affective disorder. Mol Psychiatry 13: 277-284, 2008

80. Neumann M, Seehawer M, Schlee C, Vosberg S, Heesch S von der Heide EK, Graf A, Krebs S, Blum H, Gökbuget N, et al: FAT1 expression and mutations in adult acute lymphoblastic leukemia. Blood Cancer J 4: e224, 2014.

81. de Bock CE, Ardjmand A, Molloy TJ, Bone SM, Johnstone D, Campbell DM, Shipman KL, Yeadon TM, Holst J, Spanevello MD, et al: The Fatl cadherin is overexpressed and an independent prognostic factor for survival in paired diagnosis-relapse samples of precursor B-cell acute lymphoblastic leukemia. Leukemia 26: 918-926, 2012.

82. GBD 2015 Mortality and Causes of Death Collaborators: Global, regional, and national life expectancy, all-cause mortality, and cause-specific mortality for 249 causes of death, 1980-2015: A systematic analysis for the global burden of disease study 2015. Lancet 388: 1459-1544, 2016.

83. Shariff MI, Cox IJ, Gomaa AI, Khan SA, Gedroyc W and Taylor-Robinson SD: Hepatocellular carcinoma: Current trends in worldwide epidemiology, risk factors, diagnosis and therapeutics. Expert Rev Gastroenterol Hepatol 3: 353-367, 2009.

84. Dhanasekaran R, Limaye A and Cabrera R: Hepatocellular carcinoma: Current trends in worldwide epidemiology, risk factors, diagnosis, and therapeutics. Hepat Med 4: 19-37, 2012.

85. Bray F, Ferlay J, Soerjomataram I, Siegel RL, Torre LA and Jemal A: Global cancer statistics 2018: GLOBOCAN estimates of incidence and mortality worldwide for 36 cancers in 185 countries. CA Cancer J Clin 68: 394-424, 2018.

86. Bataller R and Brenner D: Liver fibrosis. J Clin Invest 115 : 209-218, 2005

87. Farazi P and DePinho R: Hepatocellular carcinoma pathogenesis: From genes to environment. Nat Rev Cancer 6: 674-687, 2006.

88. Rosmorduc O and Housset C: Hypoxia: A link between fibrogenesis, angiogenesis, and carcinogenesis in liver disease. Semin Liver Dis 30: 258-270, 2010

89. Ferlay J, Soerjomataram I, Dikshit R, Eser S, Mathers C, Rebelo M, Parkin DM, Forman D and Bray F: Cancer incidence and mortality worldwide: Sources, methods and major patterns in GLOBOCAN 2012. Int J Cancer 136: E359-E386, 2015.
90. Argiris A, Karamouzis M, Raben D and Ferris R: Head and neck cancer. Lancet 371: 1695-1709, 2008.

91. Pai SI and Westra WH: Molecular pathology of head and neck cancer: Implications for diagnosis, prognosis, and treatment. Annu Rev Pathol 4: 49-70, 2009.

92. Kim KT, Kim BS and Kim JH: Association between FAT mutation and overall survival in patients with human papillomavirus-negative head and neck squamous cell carcinoma. Head Neck 38 (Suppl 1): S2021-S2029, 2016

93. Gupta S, Kong W, Peng Y, Miao Q and Mackillop W: Temporal trends in the incidence and survival of cancers of the upper aerodigestive tract in Ontario and the United States. Int J Cancer 125: 2159-2165, 2009.

94. Lin SC, Lin LH, Yu SY, Kao SY, Chang KW, Cheng HW and Liu CJ: FAT1 somatic mutations in head and neck carcinoma are associated with tumor progression and survival. Carcinogenesis 39: 1320-1330, 2018.

95. Katoh Y and Katoh M: Comparative integromics on FAT1, FAT2, FAT3 and FAT4. Int J Mol Med 18: 523-528, 2006.

96. Liu CJ, Liu TY, Kuo LT, Cheng HW, Chu TH, Chang KW and Lin SC: Differential gene expression signature between primary and metastatic head and neck squamous cell carcinoma. J Pathol 214: 489-497, 2008.

97. Martin D, Degese MS, Vitale-Cross L, Iglesias-Bartolome R, Valera JLC, Wang Z, Feng X, Yeerna H, Vadmal V, Moroishi T, et al: Assembly and activation of the Hippo signalome by FAT1 tumor suppressor. Nat Commun 9: 2372, 2018

98. Pennathur A, Gibson M, Jobe B and Luketich J: Oesophageal carcinoma. Lancet 381: 400-412, 2013

99. Song Y, Li L, Ou Y, Gao Z, Li E, Li X, Zhang W, Wang J, Xu L, Zhou Y, et al: Identification of genomic alterations in oesophageal squamous cell cancer. Nature 509: 91-95, 2014

100. Tran GD, Sun XD, Abnet CC, Fan JH, Dawsey SM, Dong ZW, Mark SD, Qiao YL and Taylor PR: Prospective study of risk factors for esophageal and gastric cancers in the Linxian general population trial cohort in China. Int J Cancer 113: 456-463, 2005

101. Ohashi S, Miyamoto S, Kikuchi O, Goto T, Amanuma Y and Muto M: Recent advances from basic and clinical studies of esophageal squamous cell carcinoma. Gastroenterology 149: $1700-1715,2015$

102. Li WQ, Park Y, Wu JW, Ren JS, Goldstein AM, Taylor PR, Hollenbeck AR, Freedman ND and Abnet CC: Index-based dietary patterns and risk of esophageal and gastric cancer in a large cohort study. Clin Gastroenterol Hepatol 11: 1130-1136. e1132, 2013

103. Zhang L, Zhou Y, Cheng C, Cui H, Cheng L, Kong P, Wang J, Li Y, Chen W, Song B, et al: Genomic analyses reveal mutational signatures and frequently altered genes in esophageal squamous cell carcinoma. Am J Hum Genet 96: 597-611, 2015.

104. Siegel RL, Miller KD and Jemal A: Cancer statistics, 2020. CA Cancer J Clin 70: 7-30, 2020.

105. DeSantis CE, Ma J, Gaudet MM, Newman LA, Miller KD, Sauer AG, Jemal A and Siegel RL: Breast cancer statistics, 2019. CA Cancer J Clin 69: 438-451, 2019.

106. Britt KL, Cuzick J and Phillips KA: Key steps for effective breast cancer prevention. Nat Rev Cancer 20: 417-436, 2020.

107. Wang L, Lyu S, Wang S, Shen H, Niu F, Liu X, Liu J and Niu Y: Loss of FAT1 during the progression from DCIS to IDC and predict poor clinical outcome in breast cancer. Exp Mol Pathol 100: 177-183, 2016.

108. Lee S, Stewart S, Nagtegaal I, Luo J, Wu Y, Colditz G, Medina D and Allred DC: Differentially expressed genes regulating the progression of ductal carcinoma in situ to invasive breast cancer. Cancer Res 72: 4574-4586, 2012.

109. Guo L, Qi J, Wang H, Jiang X and Liu Y: Getting under the skin: The role of CDK4/6 in melanomas. Eur J Med Chem 204 112531,2020

110. Salvador-Barbero B, Álvarez-Fernández M,Zapatero-Solana E El Bakkali A, Menéndez MDC, López-Casas PP, Di Domenico T, Xie T, VanArsdale T, Shields DJ, et al: CDK4/6 inhibitors impair recovery from cytotoxic chemotherapy in pancreatic adenocarcinoma. Cancer Cell 37: 340-353.e346, 2020.

111. Li Z, Razavi P, Li Q, Toy W, Liu B, Ping C, Hsieh W, Sanchez-Vega F, Brown DN, Da Cruz Paula AF, et al: Loss of the FAT1 tumor suppressor promotes resistance to CDK4/6 inhibitors via the hippo pathway. Cancer Cell 34: 893-905.e898, 2018 . 
112. Kang MH, Jeong GS, Smoot DT, Ashktorab H, Hwang CM, Kim BS, Kim HS and Park YY: Verteporfin inhibits gastric cancer cell growth by suppressing adhesion molecule FAT1. Oncotarget 8: 98887-98897, 2017.

113. Döhner H, Bloomfield C, Frizzera G, Frestedt J and Arthur D: Recurring chromosome abnormalities in Hodgkin's disease. Genes Chromosomes Cancer 5: 392-398, 1992.

114. Yu J and $\mathrm{Li} \mathrm{H}$ : The expression of FAT1 is associated with overall survival in children with medulloblastoma. Tumori 103: 44-52, 2017.

115. Polascik TJ, Cairns P, Chang WY, Schoenberg MP and Sidransky D: Distinct regions of allelic loss on chromosome 4 in human primary bladder carcinoma. Cancer Res 55: 5396-5399, 1995.

116. Shivapurkar N, Virmani AK, Wistuba II, Milchgrub S, Mackay B, Minna JD and Gazdar AF: Deletions of chromosome 4 at multiple sites are frequent in malignant mesothelioma and small cell lung carcinoma. Clin Cancer Res 5: 17-23, 1999.

117. Shivapurkar N, Maitra A, Milchgrub S and Gazdar AF: Deletions of chromosome 4 occur early during the pathogenesis of colorectal carcinoma. Hum Pathol 32: 169-177, 2001.

118. Chen M, Sun X, Wang Y, Ling K, Chen C, Cai X, Liang X and Liang Z: FAT1 inhibits the proliferation and metastasis of cervical cancer cells by binding $\beta$-catenin. Int J Clin Exp Pathol 12: 3807-3818, 2019.
119. Zhang H, Ramakrishnan SK, Triner D, Centofanti B Maitra D, Győrffy B, Sebolt-Leopold JS, Dame MK, Varani J, Brenner DE, et al: Tumor-selective proteotoxicity of verteporfin inhibits colon cancer progression independently of YAP1. Sci Signal 8: ra98, 2015.

120. Xu J, Wang B, Liu ZT, Lai MC, Zhang ML and Zheng SS: miR-223-3p regulating the occurrence and development of liver cancer cells by targeting FAT1 gene. Math Biosci Eng 17: 1534-1547, 2019.

121. Fan L, Campagnoli S, Wu H, Grandi A, Parri M, De Camilli E, Grandi G, Viale G, Pileri P, Grifantini R, et al: Negatively charged AuNP modified with monoclonal antibody against novel tumor antigen FAT1 for tumor targeting. J Exp Clin Cancer Res 34: 103, 2015.

122. Katoh M: Function and cancer genomics of FAT family genes (review). Int J Oncol 41: 1913-1918, 2012.

(c) (i) $\Theta$ This work is licensed under a Creative Commons Attribution-NonCommercial-NoDerivatives 4.0 International (CC BY-NC-ND 4.0) License. 